\title{
Antecedentes históricos ao surgimento do Eletromagnetismo ${ }^{+*}$
}

\author{
Daniel Gardelli ${ }^{1}$ \\ Universidade Estadual de Maringá \\ Maringá - PR
}

\section{Resumo}

No final do século XVIII não havia um consenso entre os filósofos da natureza a respeito da possibilidade de interação física entre eletricidade e magnetismo. Os seguidores do chamado Programa de Pesquisa Laplaciano acreditavam que os fenômenos elétricos eram de natureza distinta dos fenômenos magnéticos e que, portanto, uma interação eletromagnética seria impossivel de ser observada. Entretanto, os membros da corrente filosófica conhecida por Naturphilosophie defendiam a possibilidade de inter-relação entre os diferentes fenômenos observados na natureza, inclusive os elétricos com os magnéticos. Neste trabalho, analisaremos as principais características dessas duas correntes filosóficas e como a Naturphilosophie, em particular, acabou influenciando nas pesquisas do cientista dinamarquês Hans Christian Ørsted (1777-1851), que levaram ao surgimento do Eletromagnetismo.

Palavras-chave: Eletromagnetismo; Naturphilosophie; Programa de Pesquisa Laplaciano; Experimento de Ørsted.

\begin{abstract}
In the late eighteenth century, there was not a consensus among philosophers of nature regarding the possibility of physical interaction between electricity and magnetism. The followers of the so-called Laplacian Research Program believed that electrical phenomena were distinct nature of magnetic phenomena and therefore an electromagnetic
\end{abstract}

\footnotetext{
${ }^{+}$Historical background to the advent of Electromagnetism

* Recebido: agosto de 2017. Aceito: dezembro de 2017.

${ }^{1}$ E-mail: dgardelli2@uem.br
} 
interaction would be impossible to be observed. However, members of the philosophical movement known as Naturphilosophie defended the possibility of interrelation between the different phenomena observed in nature, including electrical with magnetic. In this paper, we will analyze the main features of these two philosophical currents and how Naturphilosophie, in particular, ended up influencing the research of the Danish scientist Hans Christian Ørsted (1777-1851) that led to the emergence of electromagnetism.

Keywords: Electromagnetism; Naturphilosophie; Laplacian Research Program; Ørsted's Experiment.

\section{Introdução}

Este trabalho é constituído essencialmente de duas partes. A primeira, composta pelas seções 1 e 2, diz respeito às concepções filosóficas do Programa de Pesquisa Laplaciano e da Naturphilosophie, duas correntes de pensamento que surgiram no final do século XVIII e que acabaram influenciando as pesquisas científicas, principalmente no início do século XIX. A segunda parte, composta pelas seções 3 e 4, diz respeito ao trabalho de Ørsted. Na seção 3, é apresentada a influência da Naturphilosophie sobre o seu pensamento científico; e na seção 4, a maneira como o cientista dinamarquês interpretou o resultado de seu experimento envolvendo a interação existente entre uma bússola e um fio metálico ligado a uma pilha. Na seção 5 , apresentamos nossas considerações finais.

\section{O Programa de Pesquisa Laplaciano}

No início do século XVIII, na $1^{\text {a }}$ edição de 1704 de sua obra intitulada Óptica, Isaac Newton (1642-1727) fez uma especulação sobre a existência de certos poderes atrativos capazes de agirem a distâncias imperceptíveis:

Não têm as pequenas partículas dos corpos certos poderes, virtudes ou forças por meio dos quais elas agem a distância não apenas sobre os raios de luz, refletindoos, refratando-os e infletindo-os, mas também umas sobre as outras, produzindo grande parte dos fenomenos da natureza? Pois sabe-se que os corpos agem uns sobre os outros pelas ações da gravidade, do magnetismo e da eletricidade; e esses exemplos mostram o teor e o curso da natureza, e não tornam improvável que possa haver mais poderes atrativos além desses. Porque a natureza é muito consonante e conforme a si mesma. Não examino aqui o modo como essas atrações podem ser efetuadas. $O$ que chamo de atração pode-se dar por impulso ou por algum outro meio que desconheço. Uso esta palavra aqui apenas para expressar qualquer força pela qual os corpos tendem um para o outro, seja qual for a causa. Pois devemos

Gardelli, D. 
aprender, pelo exame dos fenômenos da natureza, quais corpos se atraem e quais são as leis e propriedades da atração, antes de investigar a causa pela qual a atração se efetua. As atrações da gravidade, do magnetismo e da eletricidade alcançam distâncias bem perceptíveis, e assim têm sido observadas pelos olhos comuns, podendo haver outras que alcançam distâncias tão pequenas que escaparam à observação até aqui; e talvez a atração elétrica possa alcançar essas distâncias mínimas mesmo sem ser excitada pela fricção (NEWTON, Óptica (1704), Livro III, Questão 31, 1996, p. 274-275).

No Escólio Geral ${ }^{2}$ da $2^{\text {a }}$ edição de 1713 de sua obra intitulada Philosophiae Naturalis Principia Mathematica (Princípios Matemáticos de Filosofia Natural), também conhecida simplesmente por Principia (NEWTON, 1990; NEWTON, 2008), Newton discutiu uma série de questões filosóficas e mesmo teológicas. Em seguida, reiterou sua defesa por uma metodologia indutivista, rejeitando o uso de hipóteses na filosofia experimental, postura que já havia tomado na Questão 28, do Óptica de 1704. No entanto, após seu enfático hypothesis non fingo (eu não invento hipóteses), Newton permitiu-se especular sobre uma estranha causa, responsável pelos mais variados fenômenos:

E agora poderíamos acrescentar alguma coisa concernente a um certo espírito muito sutil que penetra e fica escondido em todos os corpos grandes, por cuja força e ação as partículas dos corpos atraem-se umas às outras quando se encontram a distâncias próximas e se unem se estão contíguas; e os corpos elétricos operam a distâncias maiores, tanto repelindo quanto atraindo os corpúsculos vizinhos; e a luz é emitida, refletida, refratada, infletida e aquece os corpos; e toda sensação é excitada e os membros dos corpos animais movem-se ao comando da vontade, propagada pelas vibrações deste espírito ao longo dos filamentos sólidos dos nervos, a partir dos órgãos sensoriais externos até o cérebro e do cérebro aos músculos. Mas estas são coisas que não podem ser explicadas em poucas palavras. Também não dispomos de uma quantidade suficiente de experiências que é necessária para determinar com precisão e demonstrar mediante que leis opera este espírito elétrico e elástico. (NEWTON, Princípios Matemáticos de Filosofia Natural (1713), Livro III, Escólio Geral, 2008, p. 331-332).

Apesar dessas especulações infrutíferas, com os resultados alcançados no estudo dos movimentos dos corpos terrestres e principalmente celestes, o Principia e o Óptica de Newton pareciam indicar o caminho a ser seguido por todos aqueles que pretendessem conhecer os fenômenos naturais.

Pierre Simon Laplace (1749-1827) sofreu grande influência do pensamento newtoniano e fez muito mais do que meramente aceitar seu legado. Ele reformulou muitas das especulações do físico inglês em linguagem matemática e dedicou-se aos problemas deixados em aberto, especialmente em relação às forças "que alcançavam distâncias tão pequenas que es-

\footnotetext{
2 Na $1^{\text {a }}$ edição do Principia, de 1687, o Escólio Geral ainda não aparecia, sendo incluído apenas na $2^{\text {a }}$ edição de 1713 e na $3^{\mathrm{a}}$ edição de 1726 , ao final do livro III.
} 
capavam à observação". Na $1^{\text {a }}$ edição de 1796 de sua obra intitulada Exposition du Système du Monde (Exposição do Sistema do Mundo), Laplace afirmou que os fenômenos da refração óptica, da ação capilar, da coesão dos corpos sólidos e suas propriedades cristalinas e também as reações químicas poderiam ser explicados através de uma força de atração exercida pelas moléculas ${ }^{3}$ constituintes da matéria e que "algumas experiências já realizadas davam a esperança de que um dia essas leis seriam perfeitamente conhecidas e então, ao aplicar o cálculo, poder-se-ia elevar a física dos corpos terrestres ao estado de perfeição que a física celeste havia alcançado graças à descoberta da gravitação universal"4.

Em 1805, com a publicação do quarto volume do Traité de Mécanique Céleste (Tratado de Mecânica Celeste), a breve passagem de 1796, fazendo alusão às forças intermoleculares, consolidar-se-ia como um verdadeiro estilo laplaciano de fazer ciência. Nesta obra aparece a ideia básica de se tentar reduzir todos os fenômenos físicos a um sistema de partículas exercendo forças atrativas e repulsivas de curto alcance umas sobre as outras.

Mas foi somente em 1823 que Laplace apresentou formalmente e de maneira definitiva sua concepção de ciência, que embora fosse newtoniana em sua origem, passou a ser conhecida como o Programa de Pesquisa Laplaciano, ou seja, a tentativa de representar em linguagem matemática os fenômenos físicos e químicos estudados pelos filósofos experimentais:

[...] Parece, portanto, natural supor, de acordo com a minha teoria, esta força de repulsão como a causa da radiação das moléculas dos corpos. Por meio dessas hipóteses, os fenômenos de expansão, do calor e do movimento de vibração dos gases são explicados em termos de forças atrativas e repulsivas que são sensíveis somente a distâncias imperceptíveis. Na minha teoria da ação capilar, reduzi os efeitos de capilaridade a forças semelhantes. Todos os fenômenos terrestres dependem de forças deste tipo, assim como os fenômenos celestes dependem da gravitação universal. Parece-me que o estudo destas forças deveria ser agora o principal objetivo da filosofia matemática. Eu ainda acredito que seria útil introduzir tal estudo nas demonstrações em Mecânica, deixando de lado considerações abstratas sobre linhas flexíveis ou inflexíveis sem massa e de corpos perfeitamente duros. Alguns estudos têm me mostrado que ao nos aproximarmos da natureza por este caminho, pode-se fazer estas demonstrações com simplicidade e muito mais clareza do que os métodos utilizados até agora (LAPLACE, Traité de Mécanique Céleste, v. 5, 1825, p. 98-99) $)^{5}$.

\footnotetext{
3 O conceito de molécula considerado por Laplace é essencialmente aquele apresentado por Lavoisier em sua obra Traité Élémentaire de Chimie (Tratado Elementar de Química), cuja 1ª edição é de 1789.

${ }^{4}$ Quelques expériences déjà faites par ce moyen, donnent lieu d'espérer qu'un jour, ces lois seront parfaitement connues; alors, en y appliquant le calcul, on pourra élever la physique des corps terrestres, au degré de perfection, que la découverte de la pesanteur universelle a donné à la physique céleste (LAPLACE, Exposition du Système du Monde, v. 2, 1796, p. 198).

5 Il paraît donc naturel d'admettre, conformément à ma théorie, cette force répulsive, comme la cause du rayonnement des molécules des corps. Au moyen de ces suppositions, les phénomènes de l'expansion, de la chaleur, et
} 
Vale lembrar que durante grande parte do século XVIII havia existido duas tradições para tratar os problemas que depois foram incorporados ao currículo da física. Por um lado, os assuntos da mecânica racional, como a estática, a dinâmica, a hidrostática, a hidrodinâmica e a mecânica celeste, foram tratados pelos grandes "geômetras" da época como problemas da matemática aplicada. Por outro lado, as ciências do calor, da eletricidade, do magnetismo e da luz foram examinadas empiricamente por homens que podem melhor ser descritos hoje em dia como "filósofos experimentais", entre os quais se incluíam os médicos, os clérigos, os filósofos, os químicos e os amadores (FRANKEL, 1977, p. 35). E foi somente na década de 1780 que dois eventos em particular prenunciaram uma era de matematização e quantificação da física experimental.

Em 1783, Laplace e Antoine Laurent de Lavoisier (1743-1794) escreveram em conjunto Mémoire sur la chaleur (Mémorias sobre o calor), um livro que representava um ponto de partida para o desenvolvimento da teoria matemática do calor no século XIX e uma união bem-sucedida entre física e matemática. $\mathrm{O}$ ambiente de pesquisa francês da época pode ser apreciado nas seguintes palavras de Lavoisier:

Se em algum momento eu adotei, sem reconhecê-los, os experimentos ou as opiniões do Sr. Berthollet, do Sr. Fourcroy, do Sr. de la Place, do Sr. Monge, ou, em geral, de qualquer um cujos princípios são os mesmos que os meus, é porque estávamos acostumados a viver juntos, a comunicar nossas ideias, nossas observações e nossos pontos de vista, de modo que se estabeleceu entre nós um tipo de troca de opiniões que muitas vezes é difícil para nós mesmos distinguir aquilo que nos pertence em particular. (LAVOISIER, Discours préliminaire au Traité Élémentaire de Chimie, $1789, p .176)^{6}$.

des vibrations des gaz, sont ramenés à des forces attractives et répulsives qui ne sont sensibles qu'à des distances imperceptibles. Dans ma théorie de l'action capillaire, j'ai ramené à de semblables forces, les effets de la capillarité. Tous les phénomènes terrestres dépendent de ce genre de forces, comme les phénomènes célestes dépendent de la gravitation universelle. Leur considération me paraît devoir être maintenant, le principal objet de la Philosophie mathématique. Il me semble même utile de l'introduire dans les démonstrations de la Mécanique, en abandonnant les considérations abstraites de lignes sans masse flexibles ou inflexibles, et de corps parfaitement durs. Quelques essais m'ont fait voir qu'en se rapprochant ainsi de la nature, on pouvait donner à ces démonstrations, autant de simplicité et beaucoup pins de clarté que par les méthodes usitées jusqu'à ce jour (LAPLACE, Traité de Mécanique Céleste, v. 5, 1825, p. 98-99). Embora apareça o ano de 1825 na capa do volume 5 do Tratado de Mecânica Celeste, os seis livros que compõem este volume (livros XI a XVI) foram publicados e datados separadamente. O livro XII, em que se encontra a passagem citada, foi publicado em abril de 1823.

6 Si quelquefois il a pu m'échapper d'adopter, sans les citer, les expériences ou les opinions de M. Berthollet, de M. de Fourcroy, de M. de Laplace, de M. Monge, et de ceux, en général, qui ont adopté les mêmes principes que' moi, c'est que l'habitude de vivre ensemble, de nous communiquer nos idées, nos observations, notre manière de voir, a établi entre nous une sorte de communauté d'opinions, dans laquelle il nous est souvent difficile à nousmêmes de distinguer ce qui nous appartient plus particulièrement (LAVOISIER, Discours préliminaire au Traité élémentaire de chimie, 1789, p. 176; Traité Élémentaire de Chimie, v. 1, 1793, p. xxviii, $2^{\mathrm{a}}$ ed.). 
Em 1784, Charles Augustin de Coulomb (1736-1806) publicou um trabalho intitulado Recherches théoriques et expérimentales sur la force de torsion et sur l'élasticité des fils de métal (Pesquisas teóricas e experimentais sobre a força de torção e sobre a elasticidade de fios de metal), determinando as leis experimentais que regem o fenômeno da torção em fios metálicos e propondo uma teoria molecular para explicar estas leis. Na verdade, este trabalho é uma extensão aperfeiçoada de um trabalho anterior de 1777, intitulado Recherches sur la meilleure manière de fabriquer les aiguilles aimantées (Pesquisas sobre a melhor maneira de produzir agulhas imantadas), contendo suas primeiras investigações sobre a torção de fios. Neste trabalho, ele determinou a proporcionalidade existente entre a força e o ângulo de torção, e sugeriu a utilização de uma balança de torção para medir forças de pequena intensidade. Os estudos de Coulomb sobre eletrostática e magnetismo resultaram diretamente desses trabalhos sobre torção de fios.

E em sete memórias sobre eletricidade e magnetismo ${ }^{7}$, publicadas entre 1785 e 1789, Coulomb relatou uma série de experimentos cuidadosos e muito engenhosos que o conduziram às leis matemáticas que descrevem tanto a ação eletrostática como a ação magnetostática, análogas à ação gravitacional elaborada por Newton em 1687.

Na primeira década do século XIX, a física experimental já se encontrava em pleno processo de transformação. Sob a liderança de Laplace e do químico Claude Louis Berthollet (1748-1822), os membros da Sociedade de Arcueil ${ }^{8}$ preocuparam-se em dar prosseguimento às ideias newtoniano-laplacianas e desenvolver uma linguagem matemática extremamente rigorosa para representar os fenômenos tratados pela física experimental que eram essencialmente qualitativos até aquele momento.

Eles procuravam utilizar forças intermoleculares de curto alcance agindo entre as moléculas da matéria ordinária e as moléculas dos então chamados fluidos imponderáveis, concebidos para explicar a constituição da luz, do calor, da eletricidade e do magnetismo. Eles acreditavam que as moléculas constituintes de cada fluido repeliam-se mutuamente, mas que em todos os casos, eram atraídas pela matéria ponderável ${ }^{9}$. Aqueles que adotavam a teoria dos

\footnotetext{
7 As sete memórias, juntamente com os trabalhos de 1777 e 1784, foram reimpressas em: POTIER, A. (ed.). Collection de Mémoires Relatifs a la Physique, publiés par la Société Française de Physique. Tome 1. Mémoires de Coulomb. Paris: Gauthier-Villars, 1884. Disponível em: <http://cnum.cnam.fr/CGI/fpage.cgi?8CA1211/3/100/416/79/316>. Acesso em: 04 mar. 2011.

${ }^{8}$ A Sociedade de Arcueil (Société d'Arcueil) representava um grupo de cientistas franceses que se reunia regularmente nos finais de semana durante os verões de 1806 a 1822 nas casas de campo de Berthollet e Laplace, no vilarejo de Arcueil localizado a cerca de $5 \mathrm{~km}$ ao sul de Paris, para discutirem o que ficou conhecido posteriormente como Programa de Pesquisa Laplaciano. Entre os cientistas que participaram desta sociedade encontramse Jean-Baptiste Biot (1774-1862), Joseph Louis Gay-Lussac (1778-1850), Siméon Denis Poisson (1781-1840) e Dominique François Jean Arago (1786-1853) (CROSLAND, M. The Society of Arcueil - A view of French Science at the time of Napoleon I, 1967).

9 A concepção de uma estrutura molecular para os fluidos imponderáveis havia sido utilizada por Benjamin Franklin desde a década de 1740, para especular sobre a natureza do fluido elétrico. Por volta de 1780, a crença de Franklin de que os fenômenos eletrostáticos pudessem ser explicados em termos de uma suposta repulsão entre as partículas do fluido elétrico e uma suposta atração entre as partículas desse fluido e as partículas da matéria ordinária ponderável já havia se tornado uma doutrina padrão (FOX, 1974, p. 93).
} 
dois fluidos para explicar os fenômenos elétricos ou magnéticos, faziam a hipótese adicional de que deveria haver uma força de atração entre as moléculas do fluido elétrico vítreo e as moléculas do fluido elétrico resinoso, assim como uma força de atração entre as moléculas do fluido magnético austral e as moléculas do fluido magnético boreal (FOX, 1974, p. 92). No entanto, para os membros desta sociedade, não poderia haver qualquer interação entre dois fluidos imponderáveis de naturezas diferentes.

Laplace e Berthollet trabalhavam em conjunto desde 1785 e eram partidários de um movimento a favor de uma nova física e uma nova química alicerçada na matemática, assim como havia sido feito com a mecânica. Berthollet escreveu na introdução do primeiro volume das Memórias de Física e de Química da Sociedade de Arcueil:

Para que os avanços de tais conhecimentos [em Física e em Química] sejam reais, e que tenham uma marcha constantemente progressiva, é preciso fornecer uma grande precisão aos fatos, é preciso aperfeiçoar todos os meios de estabelecer esses fatos e comparar os resultados obtidos por diferentes físicos, sob circunstâncias diferentes. É somente com esses esforços e com a ajuda de uma crítica saudável que se pode chegar a teorias inabaláveis, a verdades que jamais podem ser contestadas. (SOCIÉTÉ D’ARCUEIL. In: BERNARD, J. J. (ed.). Mémoires de physique et de chimie de la Société d'Arcueil, v. 1, Introduction. Paris, 1807) ${ }^{10}$.

Pode-se perceber claramente o clima intenso de troca de ideias que havia entre os pesquisadores no final do século XVIII e início do século XIX e a importância que se dava aos debates científicos com o intuito de desenvolver o Programa de Pesquisa Laplaciano. Contudo, principalmente a partir da segunda década do século XIX, este programa de pesquisa começou a perder força.

O tratamento matemático dado para a distribuição do calor em sólidos feito por JeanBaptiste Joseph Fourier (1768-1830) em 1807 surgiu como um desafio para os defensores do modelo explicativo baseado em forças intermoleculares.

De 1816 a 1823, Augustin-Jean Fresnel (1788-1827) e François Jean Dominique Arago (1786-1853) elaboraram a teoria ondulatória da luz e, com ela, conseguiram explicar todos os fenômenos ópticos conhecidos, especialmente o da dupla refração e o da polarização, de uma maneira mais simples e mais consistente do que a maneira de explicar baseada na teoria corpuscular da luz adotada pelo Programa de Pesquisa Laplaciano.

As maneiras diferentes pelas quais André-Marie Ampère (1775-1836) e Michael Faraday (1791-1867) interpretaram a interação eletromagnética anunciada por Ørsted em 1820 também ajudaram a enfraquecer o programa laplaciano. A primeira porque Ampère reduziu os

\footnotetext{
10 Pour que les progrès de ce genre de connoissances soient réels, et qu'ils aient une marche constamment progressive, il faut qu'on apporte une grande précision dans les faits, que l'on perfectionne tous les moyens qui servent à les établir, que l'on compare les résultats obtenus par différens physiciens, et dans des circonstances différentes. Ce n'est que par ces soins et à l'aide d'une saine critique, que l'on peut parvenir à des théories inébranlables, à des vérités qui ne pourront jamais être contestées (Société d'Arcueil. In: BERNARD, J. J. (ed.). Mémoires de physique et de chimie de la Société d'Arcueil, v. 1, Introduction. Paris, 1807).
} 
fenômenos magnéticos e eletromagnéticos a um fenômeno puramente eletrodinâmico, algo considerado inconcebível para Coulomb e Laplace. E a segunda porque Faraday interpretou a ação exercida por um fio condutor de eletricidade sobre uma agulha imantada como sendo devido à existência de uma "força rotacional", contrastando fortemente com as forças centrais newtoniano-laplacianas, cuja direção de atuação era a da linha reta ligando os corpos interagentes.

A teoria analítica do calor de Fourier, o triunfo da teoria ondulatória de Fresnel e Arago e o surgimento da interação eletromagnética interpretada de formas distintas por Ampère e Faraday acabaram minando as ideias compartilhadas pelos laplacianos, culminando com a retirada de Biot do cenário científico entre os anos de 1824 e 1830, cujos esforços haviam sido todos direcionados para colocar em prática aquelas ideias concebidas originalmente por Laplace e Berthollet (FRANKEL, 1977, p. 68).

\section{A Escola Filosófica Alemã da Naturphilosophie}

Nas duas últimas décadas do século XVIII surgiu na Alemanha um movimento filosófico chamado de Naturphilosophie. Para os adeptos dessa filosofia, na natureza haveria um permanente conflito de forças fundamentais que poderia se manifestar de diversas formas, dando origem aos fenômenos químicos, mecânicos, elétricos, magnéticos etc. Assim, uma determinada manifestação poderia se transformar em outra dependendo da intensidade desse conflito.

Immanuel Kant (1724-1804) foi um dos precursores desse movimento. O filósofo alemão questionou os fundamentos da mecânica newtoniana, tais como a noção de espaço absoluto e a maneira pela qual os corpos conseguem interagir entre si mesmo estando separados um do outro. Uma de suas grandes preocupações foi a de tentar demonstrar a impossibilidade de se ter acesso à natureza das coisas como elas realmente são, ou às "coisas-em-si". E um dos pontos analisados para conseguir tal intento foi a questão do conceito de força e sua função na natureza. Em seu livro Metaphysische Anfangsgründe der Naturwissenschaft (Primeiros Princípios Metafísicos da Ciência da Natureza) publicado em 1786, o filósofo de Königsberg defendeu que deviam existir apenas duas forças fundamentais na natureza, sugerindo que outros tipos de "forças" se manifestariam meramente como modificações destas últimas:

Apenas se podem pensar estas duas forças motrizes [de atração e de repulsão] da matéria. Com efeito, todo o movimento que uma matéria pode imprimir à outra, já que a este respeito cada uma delas se considera apenas como um ponto, deve sempre olhar-se como comunicada na linha reta entre dois pontos. Mas nesta reta são possiveis apenas duas espécies de movimentos: um é aquele pelo qual esses pontos se afastam um do outro; o segundo é aquele pelo qual eles se aproximam entre si. Mas a força que constitui a causa do primeiro movimento chama-se força de repulsão, e a força que é a causa do segundo denomina-se força de atração. Por conse- 
guinte, apenas se podem conceber estas duas espécies de forças, às quais se devem reduzir todas as forças motrizes da natureza material (KANT, Primeiros Princípios Metafísicos da Ciência da Natureza [1786], 1990, p. 45-46).

Para Kant, "a matéria enche o seu espaço graças às forças repulsivas de todas as suas partes, isto é, graças a uma força de expansão que lhe é peculiar". Por isso, "a matéria é impenetrável e, claro está, graças à sua força expansiva originária”. Portanto, a força fundamental de repulsão dota a matéria da propriedade de impenetrabilidade, que nada mais é do que a faculdade de extensão da matéria (KANT, Primeiros Princípios Metafísicos da Ciência da Natureza [1786], 1990, p. 46 e 51). No entanto:

[...] a matéria, graças apenas à sua força repulsiva, não se conteria em fronteira alguma da sua expansão, isto é, dispersar-se-ia até ao infinito, e em nenhum espaço determinável se encontraria uma quantidade determinável de matéria. Portanto, se existissem simplesmente forças repulsivas na matéria, todos os espaços estariam vazios e assim, em rigor, não haveria matéria alguma. Toda a matéria exige, pois, para a sua existência forças opostas às forças de expansão, isto é, forças compressivas (KANT, Primeiros Princípios Metafísicos da Ciência da Natureza [1786], 1990, p. 56-57).

Por outro lado, se existissem apenas as forças atrativas, então:

[...] as partes [da matéria] mover-se-iam umas para as outras até que entre elas nenhuma distância houvesse, isto é, confundir-se-iam num ponto matemático, e o espaço estaria vazio, por conseguinte, sem matéria alguma. Pelo que a matéria dotada apenas de forças de atração, sem forças repulsivas, é impossivel. [Desse modo,] a força repulsiva pertence igualmente à essência da matéria, tal como a força atrativa, e uma não se pode separar da outra no conceito da matéria (KANT, Primeiros Princípios Metafísicos da Ciência da Natureza [1786], 1990, p. 59).

E Kant conclui esta investigação sobre a natureza dessas forças afirmando que:

Exigir que se torne compreensível a possibilidade das forças fundamentais é algo de totalmente impossível; com efeito, elas chamam-se fundamentais justamente porque não se podem derivar de nenhumas outras, isto é, não se podem compreender. Mas a força atrativa originária não é menos incompreensível do que a repulsão primordial. Apenas não se apresenta aos sentidos de modo tão imediato como a impenetrabilidade, para nos proporcionar conceitos de objetos determinados no espaço. (KANT, Primeiros Princípios Metafísicos da Ciência da Natureza [1786], 1990, p. 61).

Essas ideias de Kant sobre as condições para a existência da matéria foram desenvolvidas por outro filósofo alemão chamado Friedrich Wilhelm Joseph von Schelling (17751854) que, aos 16 anos, já havia recebido permissão para matricular-se na Universidade de Tübingen, onde foi companheiro de estudos tanto do poeta Friedrich Hölderlin (1770-1843) 
como de Georg Wilhelm Friedrich Hegel (1770-1831), sendo muito influenciado pelas ideias filosóficas deste último.

Considerado um dos maiores representantes da escola filosófica da Naturphilosophie, ao lado de Kant e Hegel, Schelling procurava compreender a natureza em sua totalidade e estabelecer os fundamentos para as ciências físicas a partir das polaridades encontradas na natureza. Uma de suas ideias principais era a de que todas as polaridades seriam decorrentes das forças fundamentais kantianas e que o conflito e a ação recíproca dessas forças em oposição deveriam gerar todos os outros fenômenos naturais. A polaridade elétrica, a polaridade magnética, o contraste entre substâncias ácidas e básicas e várias outras dualidades eram consideradas pelos filósofos da Naturphilosophie como efeitos provenientes da polaridade fundamental da natureza dada pelas forças de atração e repulsão.

Quando contava com apenas 22 anos de idade, Schelling escreveu um livro intitulado Ideen zu einer Philosophie der Natur (Ideias para uma Filosofia da Natureza) que foi publicado em 1797, no qual se pode ler que "para manter esta troca permanente, a natureza sozinha teve de contar com contradições em todos os lugares, teve de estabelecer extremos, dentro da qual a multiplicidade interminável de seus fenômenos foi possível"11 (SCHELLING, Ideas for a philosophy of nature, p. 87. In: MARTINS, 2007, p. 361, tradução nossa).

É interessante mencionar o caso do cientista Johann Wilhelm Ritter (1776-1810) que também acreditava profundamente na unidade de todas as forças naturais, e que por volta de 1800, estava em busca de fenômenos que relacionassem um ímã com a recém-inventada pilha voltaica. Assim, ele procurou reproduzir os fenômenos da eletrólise com fios de ferros imantados, e realizou experimentos para detectar a ação de ímãs sobre rãs, mostrando que um fio de ferro imantado combinado com outro não imantado conseguia produzir contrações nos membros de uma rã (MARTINS, 1986). Outro exemplo que vale a pena ser citado é o dos cientistas Charles Hatchett (1765-1847) e Charles Bernard Desormes (1777-1862), que procuraram estabelecer interações entre polos magnéticos e cargas elétricas por volta de 1805 .

A forma de a Naturphilosophie conceber a natureza acabou influenciando profundamente o trabalho de alguns cientistas do início do século XIX, levando-os a investigar supostas relações existentes entre os diferentes fenômenos naturais, em particular, entre os efeitos elétricos e magnéticos.

\section{A influência da Naturphilosophie sobre Ørsted}

De acordo com as teorias corpusculares ortodoxas existentes no final do século XVIII e início do século XIX, a interação eletromagnética não era algo a ser esperado, pois Coulomb aparentemente havia "demonstrado" na década de 1780 que a eletricidade e o mag-

\footnotetext{
11 In order to maintain this perpetual exchange, Nature had everywhere to count upon contradictories, had to set up extremes, within which alone the endless multiplicity of her phenomena was possible (SCHELLING, Ideas for a philosophy of nature, p. 87. In: MARTINS, 2007, p. 361).
} 
netismo eram duas espécies de matéria inteiramente distintas, cujas leis de ação eram matematicamente similares, mas cujas naturezas eram fundamentalmente diferentes. A conversão de uma na outra era, portanto, impensável. Assim, aqueles que aceitaram as ideias coulombianas, simplesmente não procuravam por um efeito magnético gerado pelas correntes elétricas (WILLIAMS, 1981, p. 184).

No entanto, na mesma época, Kant considerou as duas forças de atração e repulsão como a base de todos os fenômenos materiais e disto seguiu que todas as forças da natureza seriam apenas manifestações diferentes destas forças subjacentes. Consequentemente, todas as forças da natureza deviam, por definição, se converter umas nas outras. Suas diferentes manifestações poderiam ser explicadas em termos dos diferentes modos pelos quais as forças atuavam. Portanto, diferentemente do que Coulomb e seus seguidores pensavam, o efeito magnético de uma corrente elétrica era algo que poderia ser esperado (WILLIAMS, 1962, p. 116).

Hans Christian Ørsted (1777-1851) foi um dos cientistas que sofreram grande influência da escola filosófica da Naturphilosophie. Em seu trabalho de 1799 intitulado Fundamentos da metafísica da natureza, o cientista dinamarquês já havia incorporado as ideias kantianas ao falar na introdução das forças básicas da natureza (atração e repulsão) como condições necessárias para a existência da matéria de tamanho finito:

\begin{abstract}
A força expansiva evita que a força atrativa reduza a extensão da matéria a zero, $e$ a força atrativa evita que a força expansiva dê à matéria uma extensão infinitamente grande. Elas trabalham em oposição uma à outra e produzem movimentos em direções opostas de modo que uma pode ser considerada como negativa enquanto a outra pode ser considerada como positiva (ØRSTED, Fundamentals of the metaphysics of nature, §39, 1799. In: MARTINS, 2007, p. 376-377).
\end{abstract}

Com a invenção da pilha por Alessandro Volta (1745-1827) apenas um ano depois, em 1800, foi possível ter acesso a correntes contínuas e duradouras em vez de correntes momentâneas ou de curta duração como as que eram conseguidas com a descarga de garrafas de Leiden que armazenavam cargas elétricas geradas por atrito.

Volta era partidário da teoria do fluido único (WHITTAKER, v. I, 1951, p. 58) movimentando-se pelo circuito. Em seu artigo de 1800, em que descreve seu invento chamado por ele mesmo de aparelho eletromotor ou órgão elétrico artificial ${ }^{12}$, o cientista italiano afirma que "esta circulação sem término do fluido elétrico (este movimento perpétuo) [através do fio ligando as extremidades da pilha] pode parecer paradoxal, pode não ser explicável; por outro lado é verdadeira e real, e pode ser tocada, por assim dizer, com a mão" (VOLTA, So-

12 "Este aparelho, similar na essência, como demonstrarei, e mesmo pela maneira como o construí, também na forma, ao órgão elétrico natural do torpedo [peixe elétrico], da enguia elétrica etc., mais do que às garrafas de Leiden e às baterias elétricas conhecidas, gostaria de chamá-lo de órgão elétrico artificial" (VOLTA, Sobre a eletricidade excitada pelo simples contato entre substâncias condutoras de tipos diferentes. In: MAGNAGHI; ASSIS, 2008, p. 121-122). 
bre a eletricidade excitada pelo simples contato entre substâncias condutoras de tipos diferentes. In: MAGNAGHI; ASSIS, 2008, p. 133).

Em 1775, a Academia de Ciências de Paris havia anunciado formalmente que não aceitaria mais esquemas referentes a supostas máquinas de movimento perpétuo. Isto se aplicava, no entanto, somente a movimentos perpétuos da matéria ponderável. Não havia nada na ciência do século XVIII que proibisse o movimento perpétuo da matéria imponderável. Como ela era extremamente "sutil", não havia razão para esses fluidos, uma vez colocados em movimento, deixarem de continuar a se moverem. Isto parece ter sido a ideia de Volta ao descrever o "mouvement perpetuel" do fluido elétrico em uma carta ao Cavalheiro Joseph Banks, P. R. S. (President of the Royal Society), anunciando a invenção da pilha (WILLIAMS, 1962, p. 114-115).

Independentemente de se acreditar na existência de um ou dois fluidos elétricos no interior dos fios ou de se acreditar que o movimento poderia ser perpétuo ou não, o fato é que a pilha promoveu um grande impulso às investigações eletrodinâmicas, dando início a uma busca incessante por uma relação entre eletricidade e magnetismo por aqueles que acreditavam nessa possibilidade, como Ørsted, por exemplo.

Para os partidários da teoria dos dois fluidos, inicialmente essa busca guiava-se pelas semelhanças apresentadas entre os fluidos elétricos vítreo e resinoso e os fluidos magnéticos austral e boreal, já que as moléculas de fluido elétrico de mesma natureza se repeliam e as de natureza diferente se atraíam, o mesmo ocorrendo com as moléculas de fluido magnético. Além disso, a força entre fluidos elétricos era análoga à força entre fluidos magnéticos, ou seja, inversamente proporcionais ao quadrado da distância entre duas porções de fluido.

Desse modo, no início do século XIX, tornou-se natural associar uma pilha voltaica a um ímã e a procurar-se não só interações entre os mesmos, mas também gerar com um deles os efeitos produzidos pelo outro. Em 1805, por exemplo, Hatchett e Desormes procuraram observar se uma pilha voltaica, ao ser colocada para boiar, era capaz de se orientar pelo magnetismo terrestre como uma bússola. E Ritter tentou produzir eletrólise usando um ímã no lugar de uma bateria, como mencionado anteriormente (MARTINS, 1986, p. 93).

Assim, desde o início do século, as ideias de Kant e da Naturphilosophie direcionavam as investigações de Ørsted, que acreditava profundamente na unicidade e na possibilidade de conversão das forças naturais, ou seja, na relação íntima entre eletricidade, calor, luz e magnetismo. Faltava descobrir as condições sob as quais essas conversões deveriam ocorrer.

Em 1812, Ørsted começou a falar sobre as diferentes "formas de ação" nas quais as forças fundamentais da natureza de atração e repulsão poderiam se manifestar e também que as reações químicas, a eletricidade, o magnetismo, a luz e o calor seriam manifestações das mesmas forças, de modo que, em suas palavras "tudo na física que não diz respeito à dinâmica, constitui uma ciência unificada das forças da natureza" (In: FRANKSEN, 1981, p. 26).

A obra em que ele apresentou suas ideias filosóficas foi publicada na Alemanha no mesmo ano, com o nome de Ansichten der chemischen Naturgesetze (Visão das Leis Quími- 
cas da Natureza) e foi traduzida para o francês em 1813 com o título de Recherches sur l'identité des forces chimiques et électriques (Pesquisas sobre a identidade das forças químicas e elétricas). A concepção de corrente elétrica ørstediana, e que era responsável pelo aparecimento dos fenômenos elétricos, também foi apresentada nesta obra:

Há duas forças opostas que existem em todos os corpos e que nunca podem ser subtraídas deles inteiramente. Cada uma dessas forças tem uma ação expansiva e repulsiva no volume em que cada uma é dominante; mas se atraem e produzem uma contração, quando elas reagem uma sobre a outra. A livre ação dessas forças produz os fenômenos elétricos. (ØRSTED, Recherches sur l'identité des forces chimiques et électriques, 1813, p. 248. In: WILLIAMS, 1962, p. 117).

Ørsted acreditava na existência de dois fluidos elétricos, que entravam em 'conflito' ao tentarem se movimentar em sentidos opostos dentro de um fio condutor de corrente elétrica. Este conflito dava origem a uma sucessão de interrupções e restabelecimentos do equilíbrio, manifestando-se e difundindo-se através do espaço de modo "ondulatório".

De acordo com os filósofos da Naturphilosophie, haveria na natureza um permanente conflito de forças, em que uma sempre se sobreporia à outra, de tal forma que, quando a tensão em uma manifestação, como eletricidade, por exemplo, fosse muito intensa, ela não conseguiria permanecer contida nesta forma, provocando o aparecimento de um outro fenômeno.

Seguindo esta linha de pensamento, Ørsted entendeu que o conflito elétrico seria o responsável pelo surgimento do calor, da luz e também do magnetismo. Assim como os efeitos térmicos e luminosos da corrente elétrica saem de um fio em todas as direções quando este transmite uma grande quantidade de eletricidade, ele imaginou que o efeito magnético também pudesse irradiar de forma semelhante.

Inicialmente, Ørsted utilizava somente fios muito finos, onde o "conflito elétrico" pudesse ser mais intenso, acreditando que o efeito magnético não surgiria enquanto calor e luz não fossem produzidos pela corrente galvânica (FRANKSEN, 1981, p. 25). Podemos imaginar que, assim como um relâmpago afeta as bússolas, então um fio incandescente também deveria afetá-las.

A ideia de que o efeito magnético deveria se manifestar somente quando o conflito elétrico estivesse confinado dentro de fios muito finos já havia sido proposta por Ørsted desde 1812, pois ele acreditava que ao se tornar muito intenso, este conflito não permaneceria dentro do fio, espalhando-se por todo o espaço ao seu redor e fazendo com que outros efeitos que não elétricos fossem percebidos. Portanto, ele já havia previsto a existência do efeito eletromagnético, mas estava equivocado quanto às condições necessárias para a ocorrência do fenômeno ${ }^{13}$.

\footnotetext{
13 Quanto menor o diâmetro, maior a resistência e, portanto, menor a corrente elétrica necessária para produzir o efeito sobre a agulha magnética.
} 
Finalmente, em 1820, Ørsted observou o efeito de uma corrente elétrica sobre uma agulha magnética ${ }^{14}$ e o descreveu da seguinte forma:

Os terminais opostos do aparelho galvânico são unidos por um fio metálico, que, por concisão, chamaremos de condutor de conexão ou fio de conexão. Atribuiremos o nome de conflito elétrico ao efeito que se manifesta nesse condutor e no espaço que o cerca.

A parte retilínea desse fio é colocada em posição horizontal, suspensa acima da agulha magnética, e paralela a ela. Se for necessário, o fio de conexão pode ser dobrado para que uma parte dele assuma a posição correta necessária à experiência. Nessa situação, a agulha magnética será movida, e a sua extremidade que está sob a parte do fio de conexão mais próxima ao terminal negativo do aparelho galvânico será desviada para oeste.

Se a distância entre o fio de conexão e a agulha magnética não exceder $3 / 4$ de polegada, o desvio da agulha fará um ângulo de cerca de $45^{\circ}$. Se a distância variar, o ângulo diminuirá à medida que a distância cresça. Além disso, o desvio depende da eficácia do aparelho.

[...] Se o fio de conexão é colocado em um plano horizontal sob a agulha magnética, todos os efeitos são como no plano acima da agulha, mas em direção inversa. Pois o polo da agulha magnética sob o qual está a parte do fio de conexão que está próximo ao terminal negativo do aparelho galvânico desvia-se para leste.

Para tornar mais fácil a memorização disso, pode-se usar a fórmula: $O$ polo sobre o qual entra a eletricidade negativa gira para oeste, ou para leste se entra abaixo. (ØRSTED, Experiências sobre o efeito do conflito elétrico sobre a agulha magnéti$\mathrm{ca}^{15}, 1986$, p. 116-120).

Pode-se ilustrar esse experimento da seguinte forma:

14 Para visualizar a ação exercida por um fio condutor de corrente elétrica sobre a agulha de uma bússola, acessar <http://www.youtube.com/watch?v=NwEBJBlneNE>.

15 O trabalho original de 21 de julho de 1820, escrito em latim sob o título Experimenta circa effectum conflictus electrici in acum magneticam e sua tradução para a língua inglesa podem ser encontrados em FRANKSEN, Ole Immanuel. H. C. Ørsted - A Man of the Two Cultures. Birkerød: Bang\&Olufsen, 1981. 


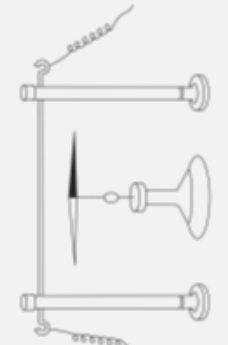

(a)

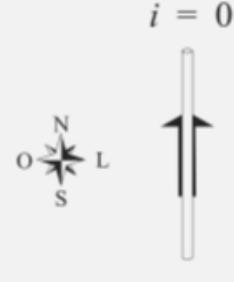

(b)

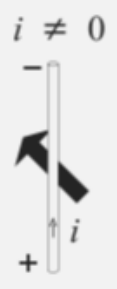

(c)

Figura 1: Representação do experimento de Ørsted com o fio sobre a agulha imantada. Em (a) e (b), a agulha aponta ao longo do meridiano magnético, sendo que não há corrente no fio; em (c), temos o desvio da agulha, com seu polo norte indo para oeste, quando flui uma corrente no fio do sul para o norte (fonte: ASSIS; CHAIB, 2011, p. 26).

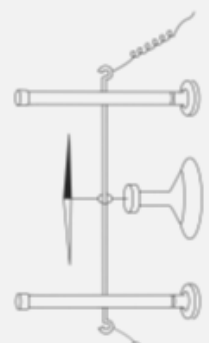

(a)

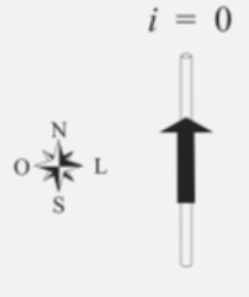

(b)

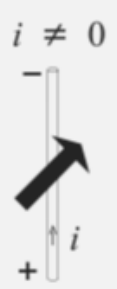

(c)

Figura 2: Representação do experimento de Ørsted com o fio sob a agulha imantada. Em (a) e (b), a agulha aponta ao longo do meridiano magnético, sendo que não há corrente no fio; em (c), temos o desvio da agulha, com seu polo norte indo para leste, quando flui uma corrente no fio do sul para o norte (fonte: ASSIS; CHAIB, 2011, p. 27).

\section{A Interpretação de Ørsted para o resultado do seu experimento}

Ørsted procurou explicar o efeito observado no experimento supondo que, em torno do fio, o conflito elétrico estivesse se manifestando sob a forma de dois turbilhões de matéria elétrica que espiralavam em torno do fio, em sentidos opostos. Um dos turbilhões deveria agir somente sobre o polo norte e o outro somente sobre o polo sul da agulha imantada:

O conflito elétrico apenas atua sobre as partículas magnéticas da matéria. Todos os corpos não-magnéticos parecem ser permeáveis ao conflito elétrico; mas os [corpos] magnéticos, ou suas partículas magnéticas, resistem à passagem desse conflito, o que faz com que possam ser movidas pelo ímpeto das forças em luta.

As observações expostas mostram que o conflito elétrico não está confinado ao fio condutor, mas está amplamente disperso no espaço circunjacente a ele.

[...] Todos os efeitos aqui expostos, relativamente ao polo norte, são facilmente compreendidos, supondo-se que a força ou matéria elétrica negativa percorre uma linha espiral dobrada para a direita, e empurra o polo norte, mas não age sobre o 
[polo] sul. Pode-se explicar de forma semelhante os efeitos sobre o polo sul, se atribuirmos à força ou matéria elétrica positiva um movimento contrário, e o poder de agir sobre o polo sul e não sobre o norte (ØRSTED, Experiências sobre o efeito do conflito elétrico sobre a agulha magnética, 1986, p. 121-122).

No artigo original de 1820, Ørsted fala de ações por contato através de empurrões exercidos pela matéria elétrica sobre os polos magnéticos. Mas, em 1821, ao tomar conhecimento dos experimentos realizados por Ampère com uma agulha astática ${ }^{16}$, que eliminava os efeitos do magnetismo terrestre sobre a agulha, ele passou a utilizar os termos atrações e repulsões entre os corpos interagentes (ØRSTED, On Electro-magnetism, November 1821, p. 323).

Mais tarde, em um artigo de 1832, e ainda sob a influência dos resultados obtidos por Ampère com a agulha astática, Ørsted descreveu o efeito da interação eletromagnética por meio de círculos e não mais por meio de espirais ou de hélices ao redor do fio:

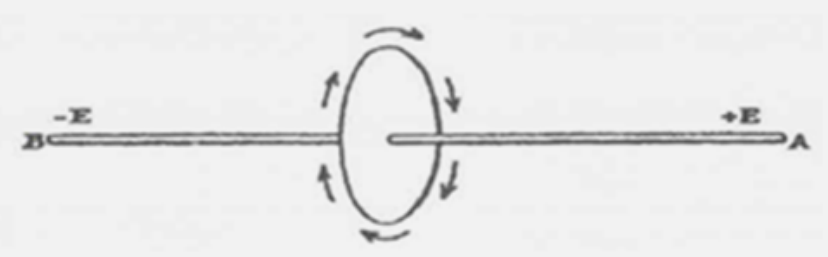

Figura 3: Desenho em anexo ao verbete Thermo-electricity da Enciclopédia de Edinburgh, escrito por Ørsted em 1832, para representar o efeito magnético de um fio retilíneo com corrente elétrica (fonte: ØRSTED, Thermo-electricity. In: BREWSTER, 1832, p. 855, fig. 1).

No mês de julho de 1820, ele [Ørsted] retomou o experimento novamente, utilizando-se de um aparelho galvânico muito mais potente. O sucesso agora era evidente, mesmo que os efeitos ainda fossem fracos nas primeiras repetições da experiência, porque ele empregava somente fios muito finos, supondo que o efeito magnético não surgiria, enquanto calor e luz não fossem produzidos pela corrente galvânica; mas ele logo descobriu que condutores de diâmetro maior produziam muito mais efeito; ele então descobriu, através de experiências contínuas durante alguns dias, a lei fundamental do eletromagnetismo, a saber, que o efeito magnético de uma corrente elétrica apresenta um movimento circular ao redor dela (ØRSTED, Thermoelectricity, 1832, p. 717).

\footnotetext{
16 O significado da palavra astática, como utilizado por Ampère, é o de equilíbrio indiferente. Ou seja, trata-se de uma agulha imantada que permanece em repouso em qualquer posição em que seja solta, não sendo afetada pelo magnetismo terrestre. Para maiores detalhes sobre o seu funcionamento, consultar (ASSIS; CHAIB, 2011, p. 61-63).
} 
Este caráter circular representava o aspecto mais intrigante e revolucionário da interação, pois aparentemente violava a simetria envolvida no fenômeno, ou seja, o efeito magnético produzido pela corrente não era nem paralelo (caso o fio se comportasse como um dipolo magnético), nem radial a ela (caso o fio se comportasse como um monopolo magnético), como se poderia esperar.

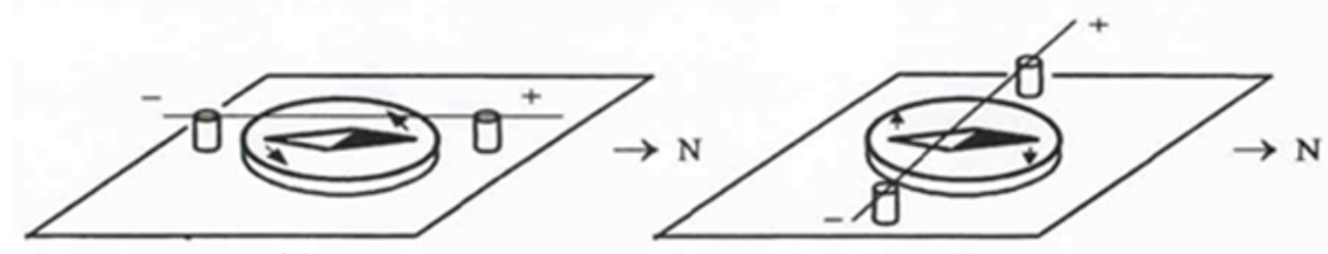

(a)

(b)

Figura 4: (a) Situação de efeito inesperado em que o polo norte da agulha (extremidade preta), com a bússola colocada verticalmente abaixo do fio com corrente, desvia-se para oeste quando uma corrente elétrica atravessa o fio no sentido de sul para norte; (b) Quando o fio era posicionado perpendicularmente à agulha, de modo que a corrente o atravessasse no sentido de leste para oeste, Ørsted esperava que a agulha girasse, posicionando-se paralelamente ao fio, mas isto não foi observado. Nesta situação, a agulha magnética tende a sofrer uma rotação no plano vertical (fonte: MARTINS, 2003, p. 255).

Obs.: Devido ao um erro tipográfico, os sinais que aparecem nas extremidades do fio tanto em (a) quanto em (b) estão invertidos. Na época, e mesmo hoje em dia, costuma-se representar o sentido da corrente elétrica através do fio indo da ponta ligada à extremidade positiva da bateria para a ponta ligada à extremidade negativa da bateria.

\section{Considerações finais}

O fato de a agulha da bússola tender a se posicionar sempre em um plano perpendicular ao fio condutor de corrente elétrica de acordo com a regra da mão direita era tão surpreendente na época que foi suficiente para abalar as estruturas da física newtoniana.

Na situação em que o fio e a agulha determinam um plano vertical de simetria, podese esperar algum movimento da agulha neste plano, como o de ser atraída ou repelida pelo fio ou ter um de seus polos atraído e o outro repelido pelo fio, mas nunca o desvio da agulha para fora do plano e sempre para o mesmo lado! O surpreendente do experimento de Ørsted é a rotação da agulha em um sentido determinado sem uma causa aparente!

A natureza da interação eletromagnética era distinta das forças conhecidas até então, já que, aparentemente, não obedecia ao princípio da ação e reação na forma forte. Ou seja, ela não parecia ser uma força central, pois não estava orientada segundo uma linha reta unindo os corpos interagentes, como acontece no caso da força gravitacional, da força eletrostática e da força magnetostática conhecidas até então.

Como foi possível perceber, a influência da Naturphilosophie foi determinante para guiar os passos seguidos por Ørsted e que o levaram a observar e interpretar a interação entre uma bússola e um fio ligado a uma pilha. 
Pode-se compreender, desta forma, a grande importância de ideias filosóficas prévias para a concepção, interpretação e aceitação do fenômeno eletromagnético e de muitos outros observados na natureza.

\section{Referências}

ASSIS, A. K. T.; CHAIB, J. P. M. de C. Eletrodinâmica de Ampère - Análise do significado e da evolução da força de Ampère, juntamente com a tradução comentada de sua principal obra sobre eletrodinâmica. Campinas, SP: Editora da Unicamp, 2011.

BERNARD, J. J. (Ed.). Mémoires de physique et de chimie de La Société d'Arcueil, Introdution. Paris, 1807. v. 1.

Disponível em: <http://fr.wikisource.org/wiki/M\%C3\%A9moires_de_physique_et_de_chimie _de_la_Soci\%C3\%A9t\%C3\%A9_d\%E2\%80\%99Arcueil/Tome_1/Introduction>. Acesso em: 01 jun. 2013.

CROSLAND, M. The Society of Arcueil - A view of French Science at the time of Napoleon I. Cambridge Mass.: Harvard University Press, 1967.

FOX, R. The rise and fall of Laplacian Physics. Historical Studies in the Physical Sciences, v. 4, p. 89-136, 1974.

Disponível em: <http://www.jstor.org/discover/10.2307/27757328?uid=3737664\&uid=2129 \&uid=2134\&uid=369125581\&uid=2\&uid=70\&uid=3\&uid=369125571\&uid=60\&sid=21101 854050971>. Acesso em: 16 mar. 2013.

FRANKEL, E. J. B. Biot and the mathematization of Experimental Physics in Napoleonic France. Historical Studies in the Physical Sciences, v. 8, p. 33-72, 1977. Disponível em: <http://www.jstor.org/discover/10.2307/27757367?uid=3737664\&uid=2134\&uid=369125581 \&uid=2\&uid=70\&uid=3\&uid=369125571\&uid=60\&purchase-type=article \&access $T y p e=$ no ne\&sid=21101864045191\&showMyJstorPss $=$ false $\&$ seq $=39 \&$ showAccess $=$ false $>$. Acesso em: 16 mar. 2013.

FRANKSEN, O. I. H. C. Ørsted: A man of the two Cultures. Birkerød: Bang\&Olufsen, 1981.

KANT, I. (1786). Primeiros Princípios Metafísicos da Ciência da Natureza. Lisboa: Edições 70, 1990. Título original: Metaphysische Anfangsgründe der Naturwissenschaft. Tradução de Artur Morão.

LAPLACE, P.-S. Exposition du Système du Monde, v. 2. Paris, 1796. Disponível em: <http://ia700500.us.archive.org/8/items/expositiondusyst02lapl/expositiondusyst02lapl.pdf>. Acesso em: 30 mar. 2013. 
Traité de Mécanique Céleste, v. 5. Paris, 1825. Disponível em: <http://ia601203.us.archive.org/8/items/traitdemcanique05lapl/traitdemcanique05lapl.pdf>. Acesso em: 30 mar. 2013.

LAVOISIER, A. L. Discours préliminaire au Traité élémentaire de chimie, 1789. Disponível em: <http://cahiers.kingston.ac.uk/pdf/cpa9.12.lavoisier.pdf>. Acesso em: 13 abr. 2013.

Traité élémentaire de chimie. 2. ed. 1793. v. 1. Disponível em: <ftp://ftp.bnf.fr/552/N5524956_PDF_1_-1DM.pdf>. Acesso em: 13 abr. 2013.

MAGNAGHI, C. P.; ASSIS, A. K. T. Sobre a eletricidade excitada pelo simples contato entre substâncias condutoras de tipos diferentes - uma tradução comentada do artigo de Volta de 1800 descrevendo sua invenção da pilha elétrica. Caderno Brasileiro de Ensino de Física, v. 25, n. 1, p. 118-140, abr. 2008. Disponível em: <http://www.ifi.unicamp.br/ assis/Cad-BrasEns-Fis-V25-p118-140\%282008\%29.pdf>. Acesso em: 08 abr. 2011.

MARTINS, R. de A. Orsted e a Descoberta do Eletromagnetismo. Cadernos de História e Filosofia da Ciência, v. 10, p. 89-114, 1986. Disponível em: <http://ghtc.ifi.unicamp.br/pdf/ram-30.pdf>. Acesso em: 27 jul. 2010.

Resistance to the Discovery of Electromagnetism: Ørsted and the Symmetry of the Magnetic Field. In: BEVILACQUA, F.; GIANNETTO, E. (Eds.). Volta and the history of electricity. Pavia, Milano: Università degli Studi di Pavia, Editore Ulrico Hoepli, 2003. p. 245-265. Disponível em: 〈http://www.ghtc.usp.br/server/pdf/RAM-Oersted1.PDF>. Acesso em: 18 mar. 2013.

Ørsted, Ritter and Magnetochemistry. In: BRAIN, R. M.; COHEN, R. S.; KNUDSEN, O. (Eds.). Hans Christian Ørsted and the Romantic Legacy in Science: Ideas, Disciplines, Practices. New York: Springer, 2007. p. 339-385. Disponível em: <http://www.ghtc.usp.br/server/pdf/RAM-magnetoquimica.PDF>. Acesso em: 21 abr. 2013.

NEWTON, I. Óptica. Tradução, introdução e notas: André Koch Torres Assis. São Paulo: Editora da Universidade de São Paulo, 1996.

Principia - Princípios Matemáticos de Filosofia Natural. Tradução: Trieste Ricci, Leonardo Gregory Brunet, Sônia Terezinha Gehring e Maria Helena Curcio Célia. São Paulo: Nova Stella / EDUSP, 1990. v. 1.

Principia - Princípios Matemáticos de Filosofia Natural. Livros II e III. Tradução: André Koch Torres Assis. São Paulo: Editora Universidade de São Paulo, 2008.

ØRSTED, H. C. Experiências sobre o efeito do conflito elétrico sobre a agulha magnética. Cadernos de História e Filosofia da Ciência, v. 10, p. 115-122, 1986. Título original: Expe- 
rimenta circa effectum conflictus electrici in acum magneticam. Tradução e comentários de Roberto de Andrade Martins do artigo original de 1820.

On Electro-magnetism. The Annals of Philosophy, v. II, n. V, p. 321-337, November 1821. Disponível em: <http://archive.org/stream/annalsofphilosop18phil\#page/321/mode/1up>. Acesso em: 22 mar. 2013.

Thermo-Electricity, v. XVII, p. 715-732. In: BREWSTER, D. (ed.). The Edinburgh

Encyclopaedia. 18 volumes. Philadelphia: Joseph Parker, 1832. Disponível em: $<$ http://archive.org/stream/edinburghencyclo17brew\#page/715/mode/1up>. Acesso em: 22 mar. 2013. [Obs.: As figuras citadas no corpo do texto encontram-se nas páginas 855 e 857 do mesmo volume]

POTIER, A. (Ed.). Collection de Mémoires Relatifs a la Physique, publiés par la Société Française de Physique. Tome 1. Mémoires de Coulomb. Paris: Gauthier-Villars, 1884. Disponível em: <http://cnum.cnam.fr/CGI/fpage.cgi?8CA121-1/3/100/416/79/316>. Acesso em: 04 mar. 2011.

WhITTAKER, E. T. A History of the Theories of Aether and Electricity. v. 1: The Classical Theories. v. 2: The Modern Theories. New York: Tomash Publishers, American Institute of Physics, 1951.

WILliAMS, L. P. Ampère's Electrodynamic Molecular Model. Contemporary Physics, v. 4, p. 113-23, 1962.

Oersted, Hans Christian. In: GILLISPIE, C. C. (ed.). Dictionary of Scientific Biography. 16 vols. New York: Charles Scribner's Sons, 1981. v. 10, p. 182-86. 